\title{
Academic Subject Areas and English Language Learning Strategies: Any Relationships?
}

\author{
Ahmad Nazari \\ Hamad Bin Khalifa University \\ Correspondence concerning this article should be addressed to Ahmad Nazari, College of Humanities and \\ Social Sciences, Hamad Bin Khalifa University, Education City, Doha, 34110, Qatar. \\ E-mail: anazari@hbku.edu.qa \\ Tanvi Warty \\ London Metropolitan University

\begin{abstract}
Correspondence concerning this article should be addressed to Tanvi Warty, London Metropolitan University, 166-220 Holloway Rd, London N7 8DB, United Kingdom.

E-mail: drtanviwarty@gmail.com
\end{abstract}

\begin{abstract}
This study is an attempt to resolve the contradictory findings concerning the relationship between learners' English language learning strategies and their academic subject areas. A two-phased mixed-methods research approach, consisting of a questionnaire and a semistructured interview, was adopted for the study. 250 students speaking English as a second language and studying five different subject areas at various London universities responded to a questionnaire on the English language learning strategies they used. The results showed that the preference for learning strategies differed significantly between students of different subject areas. Whilst cognitive strategies were reported to be the most commonly used ones by medicine and finance students, metacognitive, memory-related and social strategies were mostly used by law, music and social science students respectively. The least common set of strategies reported to be used by law and finance students was affective strategies, whereas compensatory, cognitive and metacognitive strategies were the least used ones by medicine, music and social science students in turn. A semi-structured interview was conducted with 10 of the participants to disclose the reasons behind these learners' choices of learning strategies and the contributory factors which might influence their choices. The results showed that the participants attributed their choices to factors such as the nature of their academic exposure, of their academic instructions, their learning styles, their motivations and their domestic backgrounds. The pedagogical and research significance of the study are described in the concluding remarks.
\end{abstract}

Keywords: academic subject areas, English language learning strategies, self-regulation, interaction, motivation, domestic background

London hosts an increasing number of international students with each passing year and may be considered to be amongst the most sought-after academic cities in the world. In 2016, the United Kingdom hosted $2,280,830$ international students, $38 \%$ of whom were studying at London universities, and all of whom spoke English as a Second Language (HESA, 2016). In addition to having spent a considerable amount of time studying their primary academic fields, these learners have also expended time and effort into learning
English as a second language, and will continue to do so during the course of their higher education in London. Therefore, even mere conjecture would dictate that during this time they are likely to acquire and assimilate specific strategies applicable to learning their primary academic field, the English language or indeed both. If we are to accept this premise, the need for this research becomes quite evident, i.e. if strategies, as opposed to styles, are learnable (Oxford, 2003) and different learners seem to learn differently, 
it will prompt investigating whether there is any relationship between a learner's primary academic field and her/his English language learning strategies, and if affirmative, why this relationship occurs. The authors of the current study are certainly not the first researchers to have stumbled upon the above issues. Similar questions have been posed by researchers in Malaysia (Muniandy and Shuib, 2016), Iran (Sahragard et al., 2014), Taiwan (Tuan, 2011), China (Li and Qin, 2006) and the United States of America (Gresham, 2007 ) as well. The following paragraphs provide a brief overview of the key studies and literature in this field.

Ever since the concept of learning strategies was first brought into linguistic focus by Rubin (1975), many have tried to define it. However, the most widely accepted definition and classification are those proposed by O’Malley and Chamot (1990), “Learning strategies are the special thoughts and behaviours that individuals use to help them comprehend, learn or retain new information" (p. 3). Although there have been a considerable number of proposed definitions and scales, many argue that Rebecca Oxford's 'Strategy Inventory of Language Learning (SILL)' (Oxford, 2003)is still the most comprehensive and widelyimplemented questionnaire available at present (Chang, 2011). Figure 1 succinctly depicts Oxford's classification of language learning strategies (1990):

Oxford (2011) also aptly provides a theoretical underpinning for language learning strategies by linking this concept to Vygotsky's sociocultural theory. Oxford argues that as the objective of strategy training is to help the learner to move from dependence to independence in their language learning, this training indeed scaffolds the learner to move through their Zone of Proximal Development, from other-regulation to self-regulation where the learner is metacognitively, motivationally, and behaviourally autonomous. Zimmerman (1990) highlights that self-regulated learners use their learning strategies in a systematic way and are in control of the learning process:
Undoubtedly, all learners use regulatory processes to some degree, but self-regulated learners are distinguished by (a) their awareness of strategic relations between regulatory processes or responses and learning outcomes and (b) their use of these strategies to achieve their academic goals (p. 5).

Being the term under investigation in this study, it is fitting to address studies conducted with respect to language learning strategies and academic subject areas in the past. The outcomes of the studies have provided a variety of contrasting results. A few studies have found a strong and significant link between the preferred language learning strategies employed by learners in relation to their primary academic field (Dreyer and Oxford, 1996; Psaltou-Joycey and Kantaridou, 2011; Walters, 2006; Li and Qin, 2006; Gresham, 2007), whereas Tuan (2011) and Sahragard et al. (2014) found a positive but weak link between the two variables. In contrast, McMullen (2009) and Isemonger and Sheppard (2003) found no correlation between a language learner's academic field and

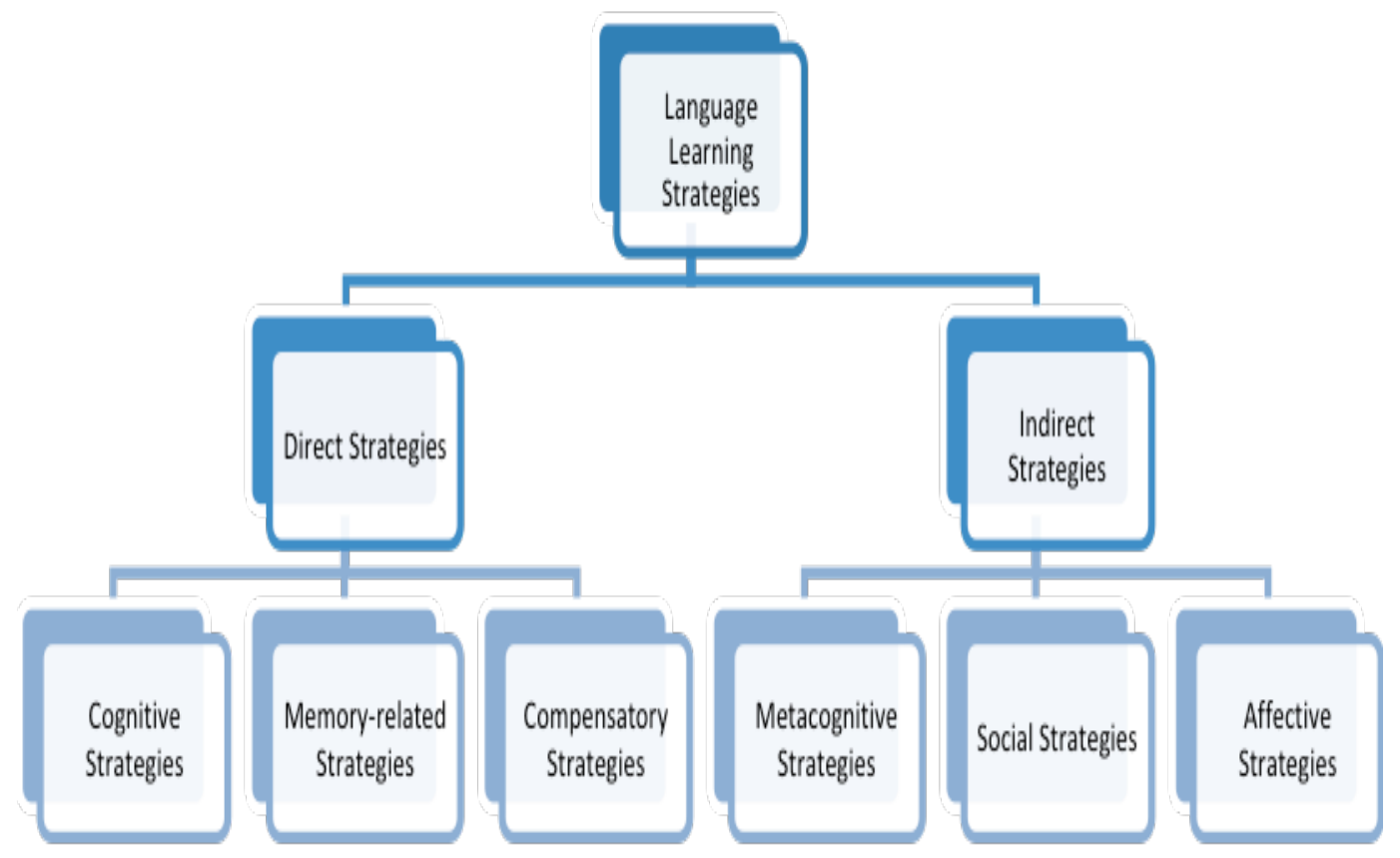

Figure 1. Oxford's classification of language learning strategies (Oxford, 1990). 
choice of language learning strategies.

A similar study conducted by Sahragard et al.in Iran probably comprises the largest sample to date, with 376 participating students. While they enlisted a large number of participants, they too used a single research tool, viz. Oxford's Strategy Inventory for Language Learning (SILL). Sahragard et al. (2014) advised future researchers to fill in the lacunae left by their study:

Future studies utilizing other data collection methods such as interviews and think-aloud protocols may produce more precise results through data triangulation... Further studies investigating the relationship between the field of study and language learning strategies and styles in other EFL and ESL contexts would contribute to the illumination of this area of study (p. 267).

Elsewhere in their article, Sahragard et al. (2014) again echo the need for more studies in this domain by stating that:

Extensive research into students' learning styles and strategies in different fields of study seems necessary. In recent years, language learning strategies and styles have been studied in relation to a number of variables in various contexts. However, thus far, few studies have examined this relationship (p. 270).

After careful consideration of the existing studies in the field, two points of interest stand out: First, a majority of the existing studies are quantitative in nature and very few investigate the factors contributing to the possible relationship between academic fields and language learning strategies. Second, the studies themselves are few and far between. While some researchers have investigated this relationship, they have also unanimously called for more research in this sphere, as evidenced by Sahragard et al. (2014) in the preceding paragraph. More recently, Muniandy and Shuib (2016) have endorsed and reiterated this necessity:

Weadvise larger samplebeused infuture studies which may be able to provide optimal findings in this area. Besides, this study only focuses on the data obtained from questionnaire - thus it limits the participants' responses. In future, interviews should be conducted, to obtain a more in-depth understanding of language learning strategies (p. 16).

Therefore, the primary objective of this research is to find any possible relationship between university students' subject areas and the types of English language learning strategies they use. The above objective, which is tackled by adopting a quantitative approach, is in fact an attempt to contribute modestly to resolving the contradictory findings concerning the relationship between language learning strategies and academic subject areas. In addition, as a secondary objective, by adopting a qualitative approach, which has not been applied adequately in previous studies of this topic, this research contributes to digging out the reasons behind these learners' choices of learning strategies and the contributory factors which may influence their choices. To address these objectives, the following research questions are formulated:

1. Is there any relationship between a learner's primary academic field and her/his English language learning strategies?

2. If yes, why does this occur?

To the above end, the following null hypothesis is put forward: There are not any significant relationships between a learner's primary academic field and her/ his English language learning strategies.

\section{Method}

\section{Participants}

In this study a stratified opportunistic sampling was adopted to select participants, i.e. students attending London universities and studying either medicine, law, finance, music or social sciences were invited to volunteer into the study. A total of 250 students (117 males and 133 females) were recruited and divided into five equal groups of fifty students each, based on their academic major at a university in London. Finally, the participants were between 18 and 60 years of age, living in London at the time the study was conducted and spoke English as a second language (see Table 1 and 2 for further demographic information). 10 students (6 females and 4 males), two from each subject area, agreed to take part in a semistructured interview. Their age range was from 19 to 28 . They spoke different L1s and were from various nationalities (see Table 1 and 2 for further demographic information). Meticulous care was taken to ensure that written and informed consent was obtained from all the participants of the study. The following section describes and analyses the data so gathered. 
Table 1

Questionnaire participants' descriptive statistics

\begin{tabular}{|c|c|c|c|}
\hline & & $\mathrm{N}$ & $\%$ \\
\hline \multirow{2}{*}{ Gender } & Male & 117 & $46.8 \%$ \\
\hline & Female & 133 & $53.2 \%$ \\
\hline \multirow[t]{5}{*}{ Subject } & Finance & 50 & $20.0 \%$ \\
\hline & Law & 50 & $20.0 \%$ \\
\hline & Medicine & 50 & $20.0 \%$ \\
\hline & Music & 50 & $20.0 \%$ \\
\hline & Social Science & 50 & $20.0 \%$ \\
\hline \multirow{18}{*}{ Language } & Hindi & 34 & $13.6 \%$ \\
\hline & Mandarin & 33 & $13.2 \%$ \\
\hline & Spanish & 30 & $12.0 \%$ \\
\hline & German & 26 & $10.4 \%$ \\
\hline & Japanese & 24 & $9.6 \%$ \\
\hline & Polish & 24 & $9.6 \%$ \\
\hline & Arabic & 21 & $8.4 \%$ \\
\hline & Gujarati & 13 & $5.2 \%$ \\
\hline & Korean & 8 & $3.2 \%$ \\
\hline & Finnish & 6 & $2.4 \%$ \\
\hline & French & 6 & $2.4 \%$ \\
\hline & Russian & 5 & $2.0 \%$ \\
\hline & Thai & 5 & $2.0 \%$ \\
\hline & Italian & 4 & $1.6 \%$ \\
\hline & Dutch & 3 & $1.2 \%$ \\
\hline & Hungarian & 3 & $1.2 \%$ \\
\hline & Portuguese & 3 & $1.2 \%$ \\
\hline & Czech & 2 & $.8 \%$ \\
\hline \multirow{3}{*}{$\begin{array}{l}\text { English Years } \\
\text { (grouped) }\end{array}$} & 1-3 years & 58 & $23.2 \%$ \\
\hline & 4-6 years & 109 & $43.6 \%$ \\
\hline & $7-9$ years & 83 & $33.2 \%$ \\
\hline
\end{tabular}

The research tools used in this study were a questionnaire on a 5-point Likert scale and a semistructured interview. The questionnaire was a modified and combined version of Oxford's Strategy Inventory for Language Learning (SILL) (Oxford, 1996) and Griffths' English Language Learning Strategy Inventory (ELLSI) (Griffiths, 2013). The results of the questionnaire data were analysed by applying a oneway ANOVA. Afterwards, a semi-structured interview was conducted with ten participants individually, covering the learner's academic and linguistic background, her/his duration and nature of exposure to English, her/his choice of English language learning strategies, and a comparative inquiry into her/his strategy use in language learning versus university studies. Once conducted, the interviews were transcribed and analysed using the procedures of the grounded theory approach (Cohen et. al., 2011).

\section{Research Design}

This study adopted a mixed-methods methodology, which due to its complementary nature, helped

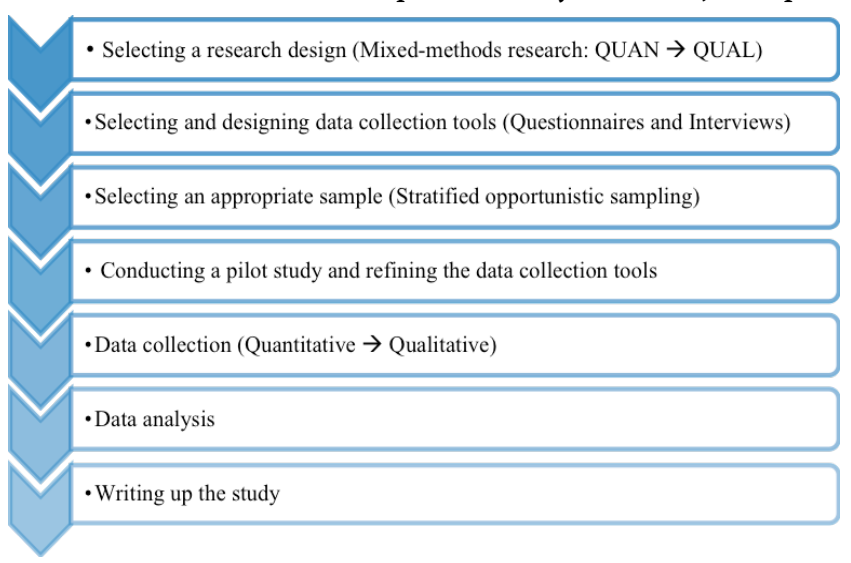

Figure 2. Sequence of data collection and analysis.

Table 2

Demographic information of the interviewees

\begin{tabular}{cccccccc}
\hline $\begin{array}{c}\text { Participant } \\
\text { Number }\end{array}$ & $\begin{array}{c}\text { Age } \\
\text { (years) }\end{array}$ & Gender & Nationality & $\begin{array}{c}\text { Duration of } \\
\text { learning English } \\
\text { (years) }\end{array}$ & $\begin{array}{c}\text { Duration of } \\
\text { stay in London } \\
\text { (months) }\end{array}$ & First Language & $\begin{array}{c}\text { Academic Field } \\
\text { at University }\end{array}$ \\
\hline 01 & 26 & Male & Spanish & 6 & 19 & Spanish & Medicine \\
02 & 26 & Male & Saudi Arabian & 8 & 18 & Arabic & Medicine \\
03 & 26 & Female & Polish & 7 & 27 & Polish & Law \\
04 & 28 & Female & Polish & 8 & Polish & Thai & Finance \\
05 & 24 & Female & Thai & 6 & 24 & Portuguese & Finance \\
06 & 24 & Male & Brazilian & 7 & Polish & Music \\
07 & 21 & Female & Polish & 4 & 12 & French & Music \\
08 & 19 & Female & French & 6 & 9 & Arabic & Social Science \\
09 & 22 & Male & Kuwaiti & 9 & Spanish & Social Science \\
10 & 26 & Female & Spanish & 5 & 14 & & \\
\hline
\end{tabular}


triangulate the obtained data, thus filling in the lacunae left behind any one method of investigation. The sequence of data collection and analysis is delineated in Figure 2.

\section{Data Analysis}

Before collecting the main study data, the questionnaire was piloted with 10 participants, similar to those taking part in the main study questionnaire, two of whom also participated in a pilot interview. These enabled the researchers to refine the research tools, making them more rigorous and thus improving the validity and reliability of resultant data (Crossman, 2017). For example, in the questionnaire, one of the items was initially phrased as "repetition helps me remember" and two of the pilot study respondents claimed that they were not sure whether that included written or oral repetition. The item was later reframed to as "I say or write new English words several times to remember them". Additionally, some items were added when they were found to be a strategy that many considered important, although they did not feature in Oxford's original Strategy Inventory for Language Learning (SILL). For example, an item as "I watch English language television or movies to improve my English language" was added after realising four of the pilot study respondents used it as an integral language learning strategy. After collecting the main study data, the results of the questionnaire data were analysed by carrying out a one-way ANOVA (see the section below for the analysis).

With respect to the interview-guide, a pilot study was conducted with two participants, similar to those taking part in the main study interview. Consequently, questions such as "Do you enjoy studying English?" or "What makes studying your subject at university rewarding?" had to be discarded because they failed to elicit any relevant data. They were reframed to extract more relevant information with minimal speaking on the interviewer's part. For example, three questions, viz., "Do you create a schedule for examinations?", "How do you plan your schedule for examinations?" and "What additional requirements do you have during examinations?" were amalgamated into one question, "What are the strategies that work best for you when preparing for an examination? And why do they work for you?" (see the section below for the analysis).

In addition to the pilot study, the methodological triangulation adopted here through the application of a mixed methods approach bridged issues of reliability and validity too (Cohen et al., 2011, p. 266).

\section{Results}

\section{ANOVA}

Concerning the results of the questionnaire, to compare the preferred English language learning strategies by academic fields, a one-way ANOVA was performed with mean scores for each strategy serving as dependent variables and academic fields serving as the comparison group variable (see Table 3). One of the assumptions of ANOVA is the homogeneity of variances. Therefore, Levene's test of equality of variance was calculated for each of the dependent variables (Glass, 1966). The results indicated that this assumption holds true for the given sample, and thus a robust version of ANOVA - a Welch test was used (Tomarken and Serlin, 1986).

Table 3

ANOVA results

\begin{tabular}{lccc}
\hline & $\mathrm{F}$ & $\mathrm{Df}$ & $\mathrm{p}$-value \\
\hline Cognitive learning strategies & 2.513 & $(4,245)$ & .045 \\
Metacognitive learning strategies & 2.850 & $(4,245)$ & .038 \\
Memory-related learning strategies & 2.563 & $(4,245)$ & .044 \\
Compensatory learning strategies & 0.925 & $(4,245)$ & .450 \\
Affective learning strategies & 0.480 & $(4,245)$ & .750 \\
Social learning strategies & 2.839 & $(4,245)$ & .026 \\
\hline
\end{tabular}

The results of the ANOVA showed that the preference for cognitive (0.045), metacognitive (0.038), memory-related (0.044) and social (0.026) learning strategies differs significantly (with $\mathrm{p}<0.05$ ) between students of different academic fields. In addition, the most common and least common set of strategies used by students of different academic fields also varied considerably (see Table 4).

Table 4

Most common and least common set of strategies used by students

\begin{tabular}{lll}
\hline Academic field & \multicolumn{1}{c}{$\begin{array}{c}\text { Most commonly } \\
\text { used strategy }\end{array}$} & $\begin{array}{c}\text { Least commonly } \\
\text { used strategy }\end{array}$ \\
\hline Medicine & Cognitive & Compensatory \\
Law & Metacognitive & Affective \\
Finance & Cognitive & Affective \\
Music & Memory-related & Cognitive \\
Social Science & Social & Metacognitive \\
\hline
\end{tabular}

\section{Grounded Theory}

Upon considering the interview data, a few strategies stand out as being useful to both the participants' respective academic fields as well as their journey through learning English as a second language. These 
strategies, which are in fact the selective codes, which in turn are the results of applying the procedures of grounded theory to the analysis of the interview data, are presented below:

1. Securing information from a variety of sources and grouping similar items together.

2. Applying logic and reasoning to organise material in the best way.

3. Learning by doing.

4. Interacting with people.

5. Evaluating one's own progress.

6. Managing oneself in academic, social and emotional contexts.

In addition, the differences in strategy use between the two domains, i.e. academic fields at university and English as a Second Language, were also evaluated and are tabulated in Table 5:

However, this was purely the researchers' interpretation of findings and could be subject to a certain degree of subjectivity. Concerning our qualitative data and analysis, we are aware that:

Qualitative research, while rigorous, inherently works with data that is subjective and contextual, which places limits on the extent to which findings can be generalised. To put it another way, the degree of the generalisability of the research findings might be one of the limitations of my study (Nazari, 2017, p. 114).

\section{Discussion}

The aim of this study was to identify significant differences, if any, between the selection and use of English language learning strategies between students of different academic fields, and the reasons for their existence. This depends upon the areas where statistically significant deviations in terms of strategy preference amongst the five fields were noted.

Sourcing Information:

A majority of students studying medicine, law and finance sought books and newspapers as the primary source of new information. Both interviewees studying medicine preferred standardised sources of English such as the Oxford English Dictionary and Thesaurus. In contrast, the students of music and social science preferred watching television or movies with subtitles to acquire new linguistic information. They seemed to attribute this preference to the passive and repeatable nature of learning that media-based sources afford. This thought is echoed by Celce-Murcia and McIntosh (1991) who believe that audio-visual modes of instructions are beneficial because they enable

Table 5

Differences in strategy use between two domains

\begin{tabular}{|c|c|c|c|}
\hline No. & Learning Strategy & Academic Field & Second Language (English) \\
\hline 1. & Defining end-points/ goals. & $\begin{array}{l}\text { Predominantly objective with well- } \\
\text { defined boundaries: Standardised exams } \\
\text { designed by the university. Distribution } \\
\text { of marks and grades on a systematic } \\
\text { scale. }\end{array}$ & $\begin{array}{l}\text { Predominantly subjective and } \\
\text { ambiguous: } \\
\text { A feeling of possessing sufficient } \\
\text { knowledge, so as to navigate effortlessly } \\
\text { through conversations. }\end{array}$ \\
\hline 2. & Practising skills before applying them. & $\begin{array}{l}\text { More feasible, since there are well- } \\
\text { defined models and step-wise guidelines } \\
\text { to proceed i.e. theory à practice. }\end{array}$ & $\begin{array}{l}\text { Less feasible, since one must attain a } \\
\text { level of confidence to speak to others in } \\
\text { the second language. }\end{array}$ \\
\hline 3. & Motivation to continue learning. & $\begin{array}{l}\text { Predominantly instrumental: to achieve } \\
\text { one's academic/ professional goals. }\end{array}$ & $\begin{array}{l}\text { Predominantly integrative: to eventually } \\
\text { merge into the target society. }\end{array}$ \\
\hline 4. & Sources of new information. & $\begin{array}{l}\text { Primarily books, academic publications } \\
\text { and newspapers. }\end{array}$ & $\begin{array}{l}\text { A wider range of sources, such as various } \\
\text { types of media and entertainment in } \\
\text { addition to books and newspapers. }\end{array}$ \\
\hline 5. & $\begin{array}{l}\text { Progression from learning to } \\
\text { interaction. }\end{array}$ & $\begin{array}{l}\text { There usually exists a preference } \\
\text { towards learning by oneself and then } \\
\text { discussing with a group/ others. }\end{array}$ & $\begin{array}{l}\text { The general preference is to interact } \\
\text { with others first and reflect upon the } \\
\text { interaction by oneself at a later date. }\end{array}$ \\
\hline 6. & $\begin{array}{l}\text { Estimating the stages of learning and } \\
\text { the time required to learn. }\end{array}$ & $\begin{array}{l}\text { Usually, there is a definite point where } \\
\text { one begins and ends, along with a } \\
\text { specified time frame. }\end{array}$ & $\begin{array}{l}\text { Very subjective, as each person begins } \\
\text { with a different level of ability and takes } \\
\text { different amounts of time to achieve the } \\
\text { same degree of proficiency. }\end{array}$ \\
\hline 7. & $\begin{array}{l}\text { Logical progression and learning } \\
\text { concepts. }\end{array}$ & $\begin{array}{l}\text { Generally a concept is learnt in theory } \\
\text { and then it is applied to a practical } \\
\text { situation. }\end{array}$ & $\begin{array}{l}\text { A significant part of learning is } \\
\text { contextually based in different } \\
\text { situations and learnt by direct exposure } \\
\text { to the practical uses of the language. }\end{array}$ \\
\hline 8. & Effects of stress. & $\begin{array}{l}\text { Stress can motivate and often improves } \\
\text { performance or, less often, hinders } \\
\text { productivity. }\end{array}$ & $\begin{array}{l}\text { Stress usually hinders communication } \\
\text { and diminishes output. }\end{array}$ \\
\hline
\end{tabular}


students to learn the language at their own pace and with as much repetition as required.

\section{Logic and reasoning}

The students of medicine and finance subscribed to the practice of identifying patterns in new information and creating condensed summaries. It may be interesting to note that both students of finance and one of medicine and one of law, attributed the use of this strategy as stemming from the requirements of their respective academic fields at university. These findings are in agreement with those of Peacock and Ho et al. (2003), Prakongchati (2007) and Sahragard et al. (2014), who identified a similar causal link.

\section{Retention of information}

Both music and law students showed a preference towards using memory-related strategies to retain new lexis; however, their approaches differed. Students of music preferred writing or speaking out loud while the students of law preferred creating acronyms and lists to better retain factual data. Another difference that emerged from the interviews is that the cohort of students studying music claimed that they found acquiring new lexis by means of listening to be easier than reading long texts, which they found tedious and boring. This general consensus was reversed in the cohort of students studying law. One possible explanation for this may be found in the studies conducted by Ho et al. (2003) and Franklin et al. (2008), which concluded that individuals exposed to training in music at or before the age of 12 were better equipped to retain verbal memory than their peers.

\section{Theory and practice}

The students of medicine and social science expressed a preference towards the former, while those studying music, law and finance appeared to prefer the latter. The former group appears to prefer a step-wise and guided progression from understanding the subject in theory and practising it in a controlled environment, followed by employing it in the real world. This may reflect the corresponding academic curricula at university level, which are so designed that episteme precedes phronesis, i.e. mastery of theoretical knowledge precedes practical application (Korthagen et al., 2001). In comparison, the latter seems to adopt a radically different and immersive approach, by first dealing with the practical aspect of communication, and then attempting to make sense of the learnt behaviour.

\section{Degree of interaction}

While the students of social science and finance appeared to be the most frequent users of social strategies while learning English, their sources of information and context seemed to differ considerably. The students of finance preferred to interact with native speakers of English and used them as models from which they could acquire lexical chunks and learn 'correct' pronunciation. Kachru (1996) is in partial agreement with this opinion and states that native speakers have a certain "Sprachgefühl" (intuitive feeling for the natural use of a language), which allows them to instinctively select the most fitting expression in a given context. However, Long (1991) argues the case for non-native conversation partners and claims that they are often more understanding than native speakers. Additionally, students of social science showed a genuine interest in learning about British cultures. A recent study conducted in Saudi Arabia found a similar correlation between students of social science and a focus on the target culture (AlHebaishi, 2012). Surprisingly, there was no significant correlation found between social language learning strategies and students of medicine and law. This runs counter to our expectations, since these are fields which, one would assume, require a substantial amount of interaction.

\section{Linguistic monitoring}

The most common set of English language learning strategies used by law students was metacognitive. This suggests that they examined their own progress and learning processes more frequently and perhaps more in depth, than others. This could be due to the fact that part of the ideal curriculum for students of law in London includes lessons on strategy development and assessing progress (Wangerin, 1987; Boyle, 2003). In comparison, students of social science seemed to favour paying attention to others while they spoke English, so as to learn from them. This mirrors the findings of Sahragard et al. (2014), whose study concluded that students of predominantly positivist sciences such as biology and engineering used metacognitive strategies more often than students of social science.

\section{Personal temperament}

The students of medicine and music showed markedly different responses to language-related stress. Interviewees from the field of medicine admitted to having dealt with highly stressful academic situations in the past and therefore seemed to have an armamentarium of strategies already in place to deal with it. Two strategies isolated from the interviews were as follows: a temporary change of 
activity such as taking a walk; and talking to a friend/ family member, preferably in their first language. In comparison, the students of music declared that they were most stressed during exams, where they were under scrutiny, which only led them to commit more mistakes than usual. Although this study shows similar quantitative results to findings of Barmeyer (2004), and Earley and Ang (2003), they differed in one key aspect. While the aforementioned authors hypothesised that affective strategies were partially influenced by cultural factors, the present study examined four culturally distinct interviewees from the fields of medicine and music i.e. French, Basque, Saudi Arabian and Catalan, who in spite of their varied backgrounds shared a similar thought-process. This leads us to introduce another causal factor which may alter a learner's attitudes towards affective strategies, viz. academic fields.

Having addressed the major differences in strategy preference amongst the five cohorts, we now examine the possible causal factors which may influence these choices.

\section{Previous academic exposure.}

The average number of years spent learning English in descending order of cohorts were finance (6.34), social science (6.22), law (5.98), medicine (5.50), and music (2.96). Also, the average number of strategies employed by the students of the five academic fields under consideration was finance (38.12), medicine (37.96), law (37.12), social science (35.90) and music (30.84). It is evident that students of finance topped both scales while the students of medicine were near the bottom of the first scale but rather high up on the second. The general assumption would be that the longer time a person has spent in academia, the more time he/she has at his/her disposal to acquire new and varied learning strategies. We find here a discrepancy in the field of medicine, which leads us to question the much accepted belief that the more time one spends studying a subject, the better one gets at it. An examination of literature found contradictory results in similar studies conducted by Peacock (2001), Melton (1990) and Reid (1987). An attempt to discern a plausible explanation for our findings revealed that it is not merely the time spent in academia, but also the nature of academic exposure and instruction which seemed to play a pivotal role in dictating strategy choice.

\section{Nature of academic exposure.}

The students of medicine and finance were often subjected to increased linguistic demands and a higher number of deadlines as compared to those of music. The two former cohorts of students appear to have undergone rigorous training in order to acquire a good score on their English proficiency tests, in addition to preparing themselves for an education where the language of instruction would be English. As opposed to this, the music students seemed to have spent the least amount of time learning English and did not view it as an integral skill for their future careers. A similar relationship was proposed by other researchers between 2001 and 2015, i.e. Wong (2015), Wong \& Nunan (2011) and Peacock (2001).

\section{Nature of instruction.}

Law and medicine students, in particular, showed a preference towards being given pre-designed materials to study from, probably in an attempt to save time. They also showed a tendency towards applying memorisation and rote-learning techniques. This may be attributed, in part, to the nature of academic material in their primary academic field. One possible explanation is that if they fail to find a logical reason or pattern, they simply accept that they must memorise the data. Studies conducted in China (Kumaravadivelu, 2003; Cross \& Hitchcock, 2007) and Hong Kong (Lee, 1996) also seem to endorse this view.

\section{Learning style preferences.}

There are two points worth mentioning here. First, while the students of social science declared that the nature of the task would determine whether they preferred learning by themselves or in a group, law students found ways and means of dealing with almost all tasks by themselves. Second, the students of music and social science were open to experimenting with strategies which did not necessarily complement their learning styles, whereas the students of medicine and law were comparatively inflexible and rigidly stuck to their preferences. Since learning styles are largely considered inherent attributes of one's personality, they may have led certain individuals, almost naturally, towards their present career paths. This view is echoed in the works of Wong (2015) and Muniandy and Shuib (2014), who propose that although learning styles may influence choice of academic major, they can also indirectly influence choice of language learning strategies.

\section{Competition and motivation.}

It appears that most students began learning English with a primary academic goal in mind, i.e., instrumental motivation; however, the more time they spent living in London, integrative motivation became more dominant . While Gardner and Lambert (1968) 
may hold their views regarding integrative motivation being a great driving force, Kumaravadivelu (2008) and Dörnyei (1998) have defended the potential of instrumental motivation being an equally important contributor to learning. In addition, medicine and law students believed that competition was fiercer in their field, which may explain why students of certain fields possess more varied English language learning strategies and a more comprehensive strategy-chain as compared to others. This could also be regarded as a wash-back effect of the varying degrees of difficulty with respect to entrance exams in different academic fields.

\section{Domestic background.}

If we consider Havighurst's theory of parental occupation, a considerable number of learning strategies and career choices may be attributed to one's domestic background (Trice et. al., 1995). Seven-tenths of interviewees in the present study appear to have chosen a field parallel to that of one of their parents and claimed that they turned to their parents for advice on academic and career choices. Thus, it might be possible that the acquisition of learning strategies may have begun even before the student stepped into school, with the parents being the primary instructors. A study conducted in 1989 determined that children whose parents were medical doctors were nearly fourteen percent more likely to be admitted into medical school than comparable nonfollowers (Lentz and Laband, 1989). Another pivotal role that family seems to play is that of responsibility and support. One of the key motivators, as stated by $6 / 10$ of the interviewees, was the fact that they wanted to make their parents proud by doing well academically, whether in ESL learning or in their respective academic fields at university. Thus, we cannot overlook the influence of family expectations and sentiments when we consider the choice of academic fields as also a desire to acquire an increasing number of English language learning strategies.

\section{Conclusion}

This study has attempted to make a contribution to the understanding of the relationship between university students' academic fields and their English language learning strategies. It has uncovered a number of statistically significant differences in English language learning strategies across five academic fields and postulated the causes for these differences, based upon triangulated data. The results, in fact, clearly showed that the null hypothesis put forward at the outset of this article was not supported. Pedagogically, the first implication of this study pertains to the way in which different English language training is imparted to students. It could be beneficial to provide students with an array of English language learning strategies irrespective of their primary academic fields, thus enabling them to make informed linguistic choices as autonomous, selfregulated learners. The second implication is directed towards the educators in the field of ESL teaching, who may be able to structure a tailor-made series of lessons for cohorts of students having common goals and academic backgrounds. Finally, the age-old concept of longer hours spent learning the language equals better fluency and accuracy needs to be challenged. It would be advantageous to examine the optimal time required to achieve language savvy and a sense of comfort with the language without the learner succumbing to exhaustion and boredom.

The first limitation of this study would lie in the nature and quantity of the sample which, while providing comparable numbers of participants, also relies upon the interest and voluntariness of the student population. Thus, the sample, not being truly randomised, can only account for the opinions of students who were willing to participate in a study, and cannot be extrapolated to the student population in general (Cohen et al., 2011). In addition, the study was conducted within the confines of the city of London and, therefore, does not capture the essence of English language learning strategies beyond these geographical boundaries. Furthermore, the shortcomings of self-reported data must also be considered. Qualitative research tools rely entirely on the veracity and accuracy of the participants' claims with respect to what they prefer and do. This is where triangulation of data may help in making decisions regarding the validity of data and its subsequent interpretations to some extent (Wong and Nunan, 2011). Drawing on the limitations of the study, similar research in more geographically and culturally diverse regions could be beneficial to the domain under investigation. In addition, other possible relationships, e.g. between learners' L1 acquisition strategies and their ESL learning strategies, are other areas worth researching.

\section{References}

Al-Hebaishi, S. M. (2012). Investigating the relationships between learning styles, strategies and the academic performance of Saudi English majors. International Interdisciplinary Journal of Education, 1(8), 510-520. Retrieved from http:// 
wsw.iijoe.org/volume1/IIJE_05_i8_v1_2012.pdf

Barmeyer, C. I. (2004). Learning styles and their impact on cross-cultural training: An international comparison in France, Germany and Quebec. International Journal of Intercultural Relations, 28(6), 577594. Retrieved from https://www.phil.uni-passau. de/fileadmin/dokumente/lehrstuehle/barmeyer/ Zeitungsartikel_pdf/47.LeaningStylesBarmeyer.pdf

Boyle, R. A. (2003). Employing active-learning techniques and metacognition in law school: Shifting energy from professor to student. University of Detroit Mercy Law Review, 81, 1-29. Retrieved from https://poseidon01.ssrn.com/delive.php?ID=9951 $030730680890850940651210900070123 \& E X T=$ pdf

Celce-Murcia, M., \& McIntosh, L. (1991). Teaching English as a second or foreign language. Boston, Massachusetts: Heinle and Heinle.

Chang, C. (2011). Language learning strategies profile of university foreign language majors in Taiwan. Electronic Journal of Foreign Language Teaching, 8(2), 201-215.

Cohen, L., Manion, L., \& Morrison, K. (2011). Research methods in education. Oxon, Oxfordshire: Routledge.

Cross, J., \& Hitchcock, R. (2007). Chinese students' view of UK HE: Differences, difficulties and benefits, and suggestions for facilitating transition. The East Asian Learner, 3(2), 1-31.

Crossman, A. (2017). Pilot study: An overview. Retrieved from https://www.thoughtco.com/pilot-study-3026449

Dörnyei, Z. (1998). Motivation in second and foreign language learning. Language Teaching, 31(3), 117135.

Dreyer, C., \& Oxford, R. (1996). Learning strategies and other predictors of ESL proficiency among Afrikaans-speakers in South Africa (Unpublished doctoral dissertation). University of Hawaii, Manoa, Honolulu.

Earley, P., \& Ang, S. (2003). Cultural intelligence: Individual interactions across cultures. Stanford, CA: Stanford Business Books.

Franklin, M. S., Sledge Moore, K., Yip, C. Y., Jonides, J., Rattray, K., \& Moher, J. (2008). The effects of musical training on verbal memory. Psychology of $\mathrm{Mu}$ sic, 36(3), 353-365.

Glass, G. V. (1966). Testing homogeneity of variances. American Educational Research Journal, 3(3), 187-190.

Gresham, G. (2007). An invitation into the investigation of the relationship between Mathematics anxiety and learning styles in elementary pre-service teachers. Journal of Invitational Theory and Practice, 13, 24-31.

Griffiths, C. (2013). The strategy factor in successful language learning. Bristol, UK: Multilingual Matters.

Higher Education Statistics Agency (HESA). (2016).
Student data and analysis. Retrieved from https:// www.hesa.ac.uk/data-and-analysis/students

Ho, Y. C., Cheung, M. C., \& Chan, A. S. (2003). Music training improves verbal but not visual memory: Cross-sectional and longitudinal explorations in children. Neuropsychology, 17(3), 439.

Isemonger, I. M., \& Sheppard, C. (2003). Learning styles. RELC Journal, 34, 195-222.

Kachru, B. B. (1996). World Englishes. Cambridge, UK: Cambridge University Press.

Korthagen, F. A., Kessels, J., Koster, B., Lagerwerf, B., \& Wubbels, T. (2001). Linking practice and theory: The pedagogy of realistic teacher education. London, UK: Routledge.

Kumaravadivelu, B. (2003). A postmethod perspective on English language teaching. World Englishes, 4(22), 539-550.

Kumaravadivelu, B. (2008). Cultural globalization and language education. New Haven, CT: Yale University Press.

Lambert, W. E., Gardner, R. C., Olton, R., \& Tunstall, K. (1968). A study of the roles of attitudes and motivation in second-language learning. Readings in the sociology of language (pp. 473-491). The Hague, South Holland: Mouton Publishers.

Lee, W. O. (1996). The Chinese learner: Cultural, psychological and contextual influences. Victoria, Australia: The Australian Council for the Educational Research.

Lentz, B. F., \& Laband, D. N. (1989). Why so many children of doctors become doctors: Nepotism vs. human capital transfers. Journal of Human Resources, 24(3), 396-413.

Li, J., \& Qin, X. Q. (2006). Language learning styles and strategies of tertiary-level English learners in China. Regional Language Center Journal, 37(1), 67-89.

McMullen, M. G. (2009). Using language learning strategies to improve the writing skills of Saudi EFL students: Will it really work? System, 37(3), 418-433.

Melton, C. D. (1990). Bridging the cultural gap: A study of Chinese students' learning style preferences. $R e-$ gional Language Center Journal, 21(1), 29-47.

Muniandy, J., \& Shuib, M. (2016). Learning styles, language learning strategies and fields of study among ESL learners. Malaysian Journal of ELT Research, 12(1), 1-19.

Nazari, A. (2017). Dynamic assessment in higher education English language classes: A lecturer perspective. The Journal of Language Teaching and Learning, 7(1), 100-118.

O’Malley, J. M., \& Chamot, A. U. (1990). Learning strategies in second language acquisition. Cambridge, $\mathrm{UK}$ : Cambridge University Press.

Oxford, R. L. (2011). Teaching and researching language learning strategies. Harlow, UK: Pearson Education.

Oxford, R. L. (2003). Learning style \& strategies. Oxford, UK: GALA. Retrieved from http://web.ntpu.edu. 
tw/ language/workshop/read2.pdf

Oxford,R.L.(1996).Employing a questionnairetoassess the use of language learning strategies. Applied Language Learning, 7(1), 28-47.

Oxford, R. L. (1990). Language learning strategies: What every teacher should know. Boston, Massachusetts: Cengage Learning.

Peacock, M. (2001). Match or mismatch? Learning styles and teaching styles in EFL. International Journal of Applied Linguistics, 11(1), 1-20.

Peacock, M., \& Ho, B. (2003). Student language learning strategies across eight disciplines. International Journal of Applied Linguistics, 13(2), 179-200.

Prakongchati, N. (2007). Factors related to the use of language learning strategies by Thai Public University Freshmen (Unpublished doctoral dissertation). Suranaree University of Technology, Nakhon Ratchasima, Thailand.

Psaltou-Joycey, A. \& Kantaridou, Z. (2011). Major, minor, and negative learning style preferences of university students. System, 39, 103-112.

Reid, J. (1987). The learning style preferences of ESL students. TESOL Quarterly, 21, 87-111.

Rubin, J. (1975). What the 'good language learner' can teach us. TESOL Quarterly, 9(1), 41-51.

Sahragard, R., Khajavi, Y., \& Abbasian, R. (2014). Field of study, learning styles, and language learning strategies of university students: are there any relations? Innovation in Language Learning and Teaching, 10(3), 255-271.
Tomarken, A. J., \& Serlin, R. C. (1986). Comparison of ANOVA alternatives under variance heterogeneity and specific noncentrality structures. Psychological Bulletin, 99, 1-90.

Trice, A. D., Hughes, M. A., Odom, C., Woods, K., \& McClellan, N. C. (1995). The origins of children's career aspirations IV. Testing hypotheses from four theories. The Career Development Quarterly, 43(4), 307-322.

Tuan, L. T. (2011). EFL learners' learning styles and their attributes. Mediterranean Journal of Social Sciences, 2, 299-320.

Walters, J. (2006). Methods of teaching inferring meaning from context. Regional Language Center Journal, 37(2), 176-190.

Wangerian, P. T. (1987). Learning strategies for law students. Albany Law Review, 52(2), 471-528.

Wong, L. L., \& Nunan, D. (2011). The learning styles and strategies of effective language learners. System, 39(2), 144-163.

Wong, W. L. H. (2015). A study of language learning style and teaching style preferences of Hong Kong Community College students and teachers in English for academic purposes (EAP) contexts (Unpublished doctoral dissertation). University of Canterbury, Christchurch, New Zealand .

Zimmerman, B. J. (1990). Self-regulated learning and academic achievement: An overview. Educational Psychologist, 25(1), 3-17. 